\title{
CMOS Realization of VDVTA and OTA Based Fully Electronically Tunable First Order All Pass Filter with Optimum Linearity at Low Supply Voltage $\pm 0.85 \mathrm{~V}$
}

\author{
Ghanshyam Singh \\ Department of Electronics and Communication Engineering, Jayamukhi Institute of Technological Sciences Affiliated to JNTUH, \\ Warangal, India \\ Email: ghanshyamsingh_09@rediffmail.com
}

How to cite this paper: Singh, G. (2020) CMOS Realization of VDVTA and OTA Based Fully Electronically Tunable First Order All Pass Filter with Optimum Linearity at Low Supply Voltage $\pm 0.85 \mathrm{~V}$. Circuits and Systems, 11, 39-49.

https://doi.org/10.4236/cs.2020.114004

Received: March 5, 2020

Accepted: April 27, 2020

Published: April 30, 2020

\section{Copyright $\odot 2020$ by author(s) and} Scientific Research Publishing Inc. This work is licensed under the Creative Commons Attribution International License (CC BY 4.0). http://creativecommons.org/licenses/by/4.0/

\begin{abstract}
This paper presents a new first order all pass filter configurations. The proposed all pass filter configuration employs two configurations namely VDVTA and OTAs based first order all pass filter configuration. The first proposed configuration employs a single VDVTA and one grounded capacitor whereas the second proposed configuration employs two OTAs and one grounded capacitor. Both types of proposed configurations are fully electronically tunable and their quality factors do not depend on tunable pole frequency range. The reported configurations yield low active and passive sensitivities and also have low power consumption with very low supply voltage \pm $0.85 \mathrm{~V}$ with Bias Voltage $\pm 0.50 \mathrm{~V}$. The PSPICE simulation of the proposed VDVTA and two OTAs based first order all pass filter configurations are verified using $0.18 \mu \mathrm{m}$ CMOS Technology Process Parameters.
\end{abstract}

\section{Keywords}

Operational Transconductance Amplifier (OTA), Voltage Differencing Transconductance Amplifier (VDVTA), CMOS Technology

\section{Introduction}

Due to recent development in the fields of microelectronics, analog signal processing as well as digital signal processing and all the fields of communication, size of the transistors and power supplies are reduced. Last few decades, current mode active building blocks have been evolved in the realization of ac- 
tive filters and oscillators. Current mode building blocks have higher bandwidth, higher dynamic range and higher slew rate with low power consumption. First order all pass filter and higher order filters are widely used in the fields of analog signal processing, measurement, instrumentation, voice or audio frequency range. The magnitude characteristics play vital role due to insensitivity of ear and Biomedical applications. Recently, most widely active building blocks are used in the designing oscillators, grounded Inductor and active filter applications. These active building blocks namely operational Amplifier, Current-mode current, gain first-order all pass filters employing CFTAs [1], A voltage-mode first order all pass filter based on VDTA [2], Voltage-mode all-pass filters including minimum component count circuits [3], Voltage-mode cascadable all-pass section using single active element [4], Single VDVTA Based Voltage-Mode Biquad Filter [5], Single MO- CCCCTA-Based Electronically Tunable Current/Trans-Impedance-Mode Biquad Universal Filter [6], Electronically Tunable Low Voltage Mixed-Mode Universal Biquad Filter [7], Current-tunable current-mode all-pass section using DDCC [8], Electronically tunable first-order all pass section using OTAs [9], Current-mode multi phase sinusoidal oscillator using CDTA-based all pass sections [10], New resistorless and electronically tunable realization of dual-output VM all-pass filter using VDIBA [11], Cascadable Current-mode first order all-pass filter based on minimal components [12], Voltage-mode all-pass filters using universal voltage conveyor and MOSFET-based electronic Resistors [13], Voltage mode cascadable all-pass sections using single active element and grounded passive components [14], Electronically tunable first-order all-pass circuit employing DVCC [15], Novel voltage-mode all-pass filter based on using DVCCs [16], A Resistorless realization of the first-order all-pass filter [17], High input impedance voltage-mode first-order all-pass sections [18], Unity/variable-gain voltage-mode/current-mode first-order all-pass filters using single DXCCII [19], First-order voltage-mode all-pass filter employing one active element and one grounded capacitor [20], Component reduced all-pass filter with a grounded capacitor and high-impedance input [21], Realization of Grounded Inductor Based Band Pass Filter Design to Achieve Optimum Linearity with Bandwidth using Single VDVTA [22], Multi output filter and four phase sinusoidal oscillator using CMOS DX-MOCCII [23], FDCCII based Electronically Tunable Voltage Mode Biquad Filter [24], CDBA Based Inverse Filter [25].

\section{Description of the Proposed Active Building Blocks VDVTA and OTA for First Order All Pass Filter}

The symbolical representation of the VDVTA as an active element is shown in Figure 1 contains three input terminals namely $\mathrm{P}, \mathrm{N}, \mathrm{V}$ and $\mathrm{Z}, \mathrm{X}^{+}, \mathrm{X}^{-}$are output terminals. All input terminals and output terminals exhibit high impedance values. The symbolic representation of OTA is shown in Figure 2(a) and Figure 2(b) represents Equivalent Circuit of OTA respectively. The symbolical representation of the VDVTA as an active element is shown in Figure 1 contains three input terminals namely $\mathrm{P}, \mathrm{N}, \mathrm{V}$ and $\mathrm{Z}, \mathrm{X}^{+}, \mathrm{X}^{-}$are output terminals. All 


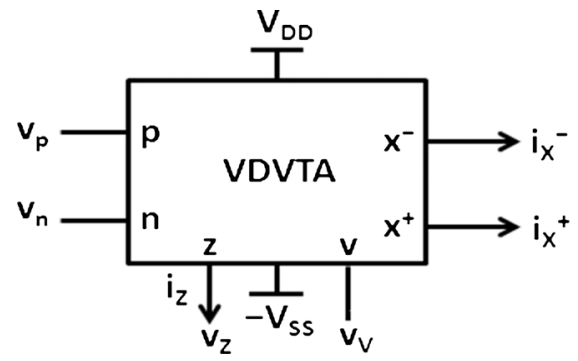

Figure 1. Symbolic representation of VDTA.

(a)

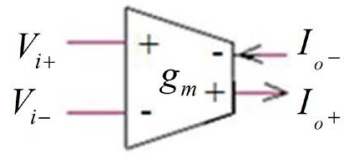

(b)

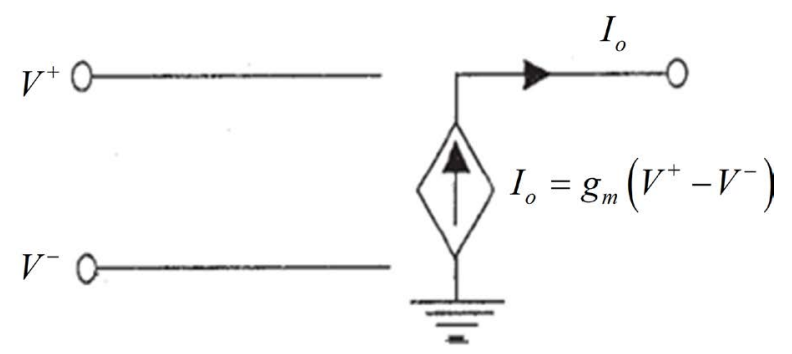

Figure 2. (a) Symbolic Notation of OTA; (b) Equivalent Circuit of OTA.

input terminals and output terminals exhibit high impedance values.

The characteristics equations of the proposed VDVTA as active building blocks for realization of first order all pass filter can be reported as Equation (1.0):

$$
\begin{gathered}
{\left[\begin{array}{l}
I_{X+} \\
I_{X-} \\
I_{Z}
\end{array}\right]=\left[\begin{array}{ccc}
0 & 0 & g_{m 2} \\
0 & 0 & -g_{m 2} \\
g_{m 1} & -g_{m 1} & 0
\end{array}\right]\left[\begin{array}{l}
V_{N} \\
V_{Z}-V_{V} \\
V_{P}
\end{array}\right]} \\
I_{x+}=g_{m_{2}}\left(V_{z}-V_{v}\right) \\
I_{x-}=-g_{m_{2}}\left(V_{z}-V_{v}\right) \\
I_{z}=g_{m_{1}}\left(V_{p}-V_{n}\right)
\end{gathered}
$$

The currents $I_{x+}, I_{x-}$ and $I_{z}$ are characterized by the Equations (1.1). (1.2) and (1.3). The operational transconductance amplifier is the basic building block for realizing all pass filter and $I_{o}$ is the output current of proposed OTA as an active building block. All terminals of OTA exhibit high impedance values. For an ideal OTA the transconductance $\mathrm{g}_{m}$ and the output current $\mathrm{I}_{\mathrm{o}}$ is characterized by Equation (2.0)

$$
I_{o}=g_{m}\left(V_{+}-V_{-}\right)
$$

The transfer functions of transadmittance mode all pass filter are employed single VDVTA with one grounded capacitor is shown in Figure 3 and two OTAs with one grounded capacitor is shown in Figure 4. 


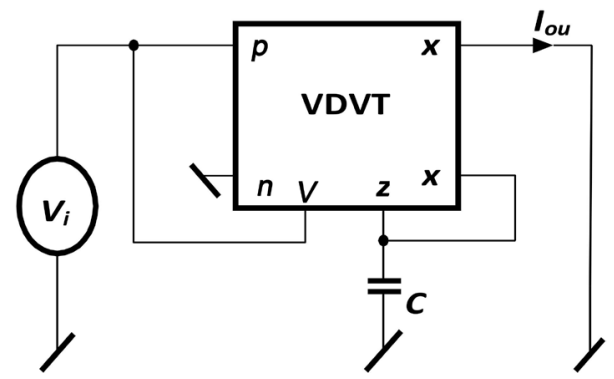

Figure 3. Proposed VDVTA based all pass filter.

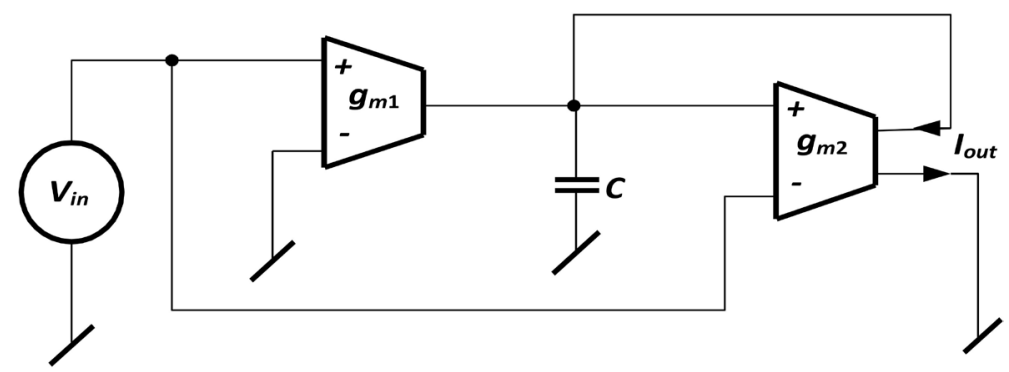

Figure 4. Proposed OTA based all pass filter.

The transfer functions of transadmittance mode all pass filter is given in Equation (2.1)

$$
\left|\frac{I_{\text {out }}}{V_{\text {in }}}\right|_{A P F}=\left(\frac{g_{m 1}-S C}{g_{m 2}+S C}\right) g_{m 2}
$$

The proposed transimpedance mode all pass filter using two OTAs.

OTAs contains high impedance input terminals and the implementation of the proposed transimpedance mode all pass filter using single VDVTA and one grounded capacitor respetively.

Transfer function of proposed OTAs based all pass filter is characterized by the Equation (2.2):

$$
\left|\frac{V_{o u t}}{V_{i n}}\right|_{A P F}=\left(\frac{G_{m 1}}{G_{m 2}+S C_{1}+2 g_{0}}\right)
$$

The phase margin and gain of the proposed all pass filters using two VDVTA and OTAs can be described in Equation (2.3):

$$
\frac{V_{o}(s)}{V_{\text {in }}(s)}=\varphi(\varpi)=180^{\circ}-2 \tan ^{-} 1(\varpi R C)
$$

\section{CMOS Simulation Result}

The CMOS Simulation result shows that the workability and functionality of the proposed VDVTA and OTAs based first order all pass filters have been verified using PSPICE. The aspect ratios of MOS transistor for OTA and VDVTA are reported in Table 1. The CMOS realization of the proposed VDVTA and OTAs based first order all pass filters are shown in Figure 5 and Figure 6 respectively. The proposed first order filter configurations are biased with VDD $=-$ VSS $=$ 
Table 1. Aspect Ratio of MOS Transistors for OTA and VDVTA.

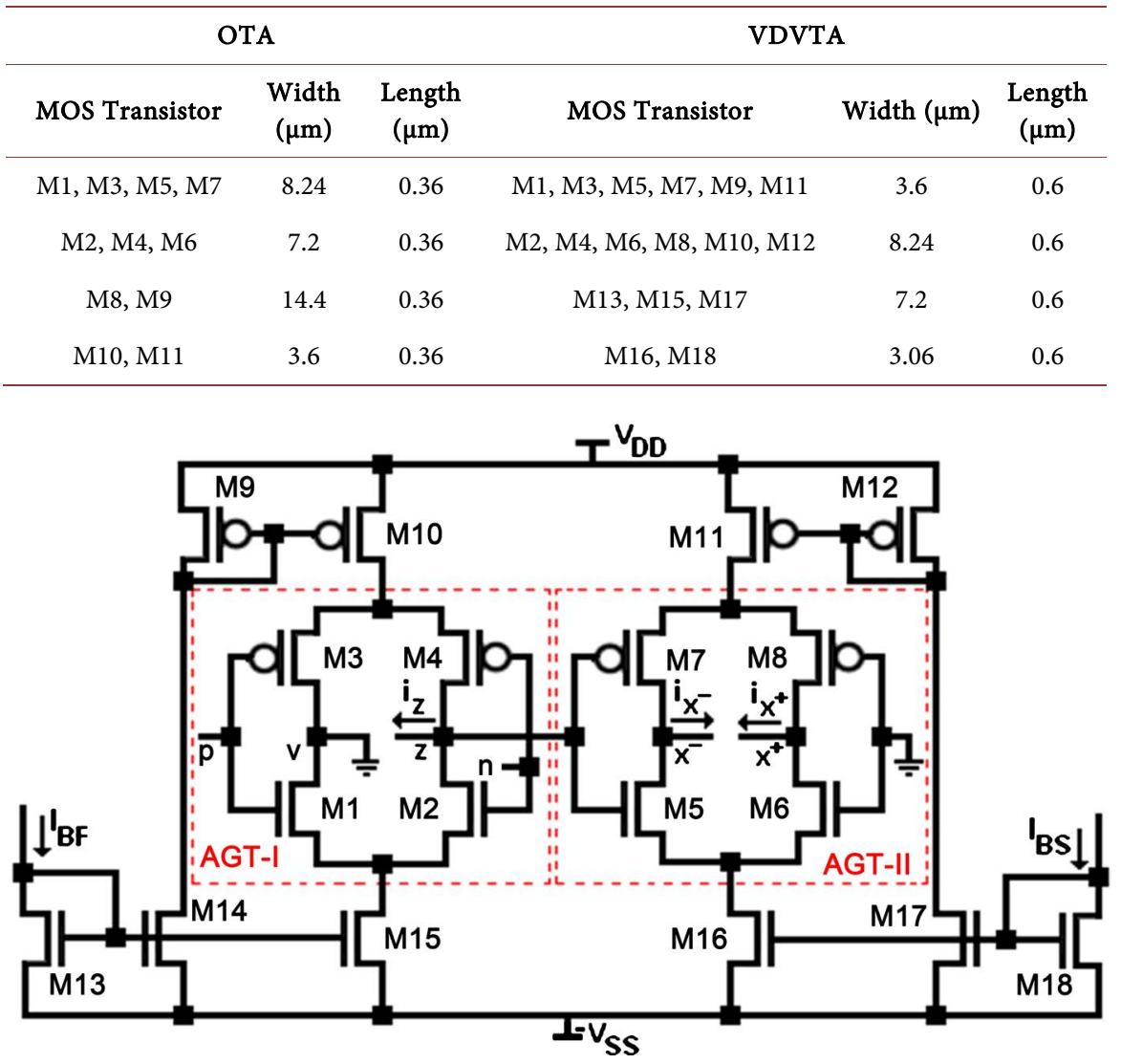

Figure 5. CMOS Realization of VDVTA Based All Pass Filter.

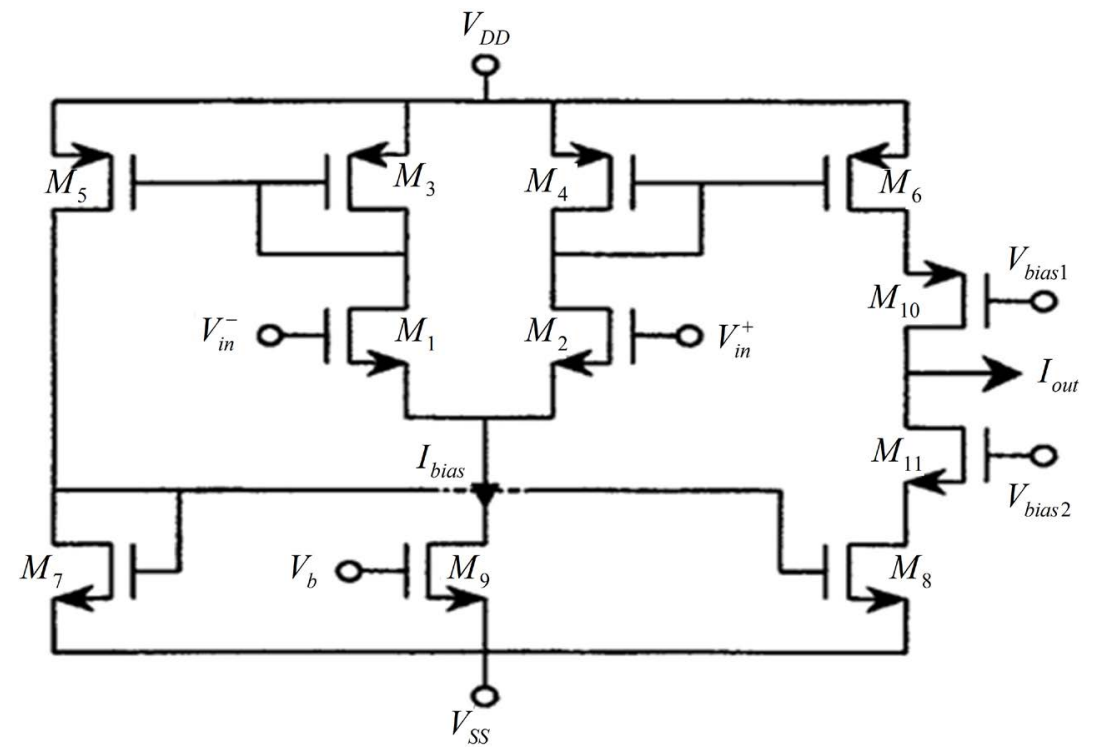

Figure 6. CMOS Realization of OTA for the proposed First order all pass filter.

$\pm 0.5 \mathrm{~V}$ with transconductances at different bias currents are $g_{m 1}=g_{m 2}=68.96$ $\mu \mathrm{A} / \mathrm{V}-103.7 \mu \mathrm{A} / \mathrm{V}$ for $I_{\text {Bias }}=10 \mu \mathrm{A}, g_{m 1}=g_{m 2}=86.24 \mu \mathrm{A} / \mathrm{V}-104.65 \mu \mathrm{A} / \mathrm{V}$ for $I_{\text {Bias }}=20 \mu \mathrm{A}, I_{\text {Bias }}=30 \mu \mathrm{A}, g_{m 1}=g_{m 2}=789 \mu \mathrm{A} / \mathrm{V}$ for $I_{\text {Bias }}=50 \mu \mathrm{A}-70 \mu \mathrm{A}, g_{m 1}=$ 
$g_{m 2}=68.16-734 \mu \mathrm{A} / \mathrm{V}$ for $I_{\text {Bias }}=100 \mu \mathrm{A}-150 \mu \mathrm{A}, g_{m 1}=g_{m 2}=86.16-734 \mu \mathrm{A} / \mathrm{V}$ $I_{\text {Bias }}=170 \mu \mathrm{A}-300 \mu \mathrm{A}$. The simulated gain magnitude response $24 \mathrm{~dB}-35.13 \mathrm{~dB}$ of OTAs based first order all pass filter is in Figure 7 and the transient response of input and output for proposed first order all pass filters configuration is presented for 0 - $60 \mathrm{mV}$ input and output signal as shown in Figure 8. The Table 2 presents the comparison of the proposed first order all pass filter configuration with the previous reported all pass filter configurations. The percentage of total harmonic distortion for the input of proposed first order all pass filters configuration is observed $1.21 \%-2.83 \%$ with minimum power dissipation $1.6 \mathrm{~mW}-4.76 \mathrm{~mW}$ as shown in Figure 9 and the simulated phase margin of VDVTA based first order all pass filter is approximately from 0 to 180 and 0 to $360 \mathrm{deg}$ or vice versa as shown in Figure 10. The pole frequency varies with $90 \mathrm{deg}$ at $1.53 \mathrm{KHz}-10.498 \mathrm{MHz}$ The simulated frequency response of proposed all pass filter configuration is presented in Figure 11 which yields open loop gain of is $5.045-6.020 \mathrm{~dB}$ and typical values $30 \mathrm{~dB}-71 \mathrm{~dB}$ with 4.10 $\mathrm{nV} / \sqrt{\mathrm{Hz}}$ at the input and $3.8 \mathrm{nV} / \sqrt{\mathrm{Hz}}$ noise spectral density at the cut off

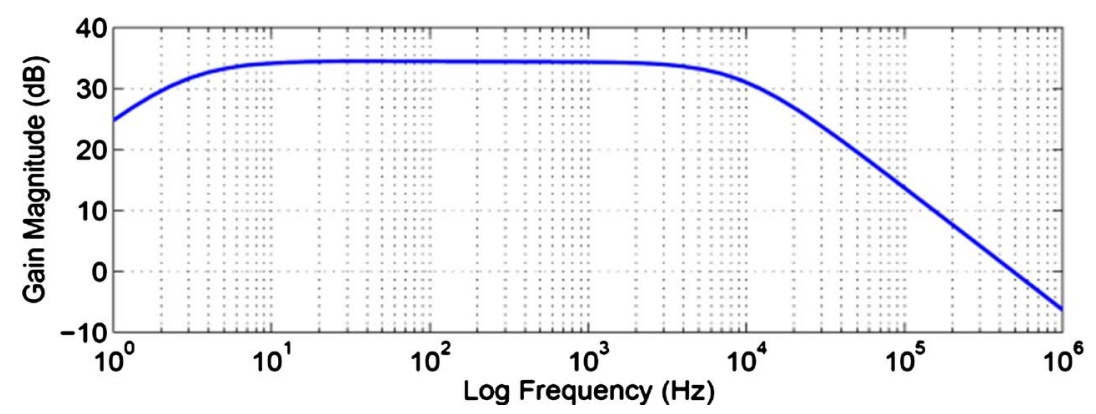

Figure 7. Simulated gain magnitude response of proposed OTA based all pass filter.

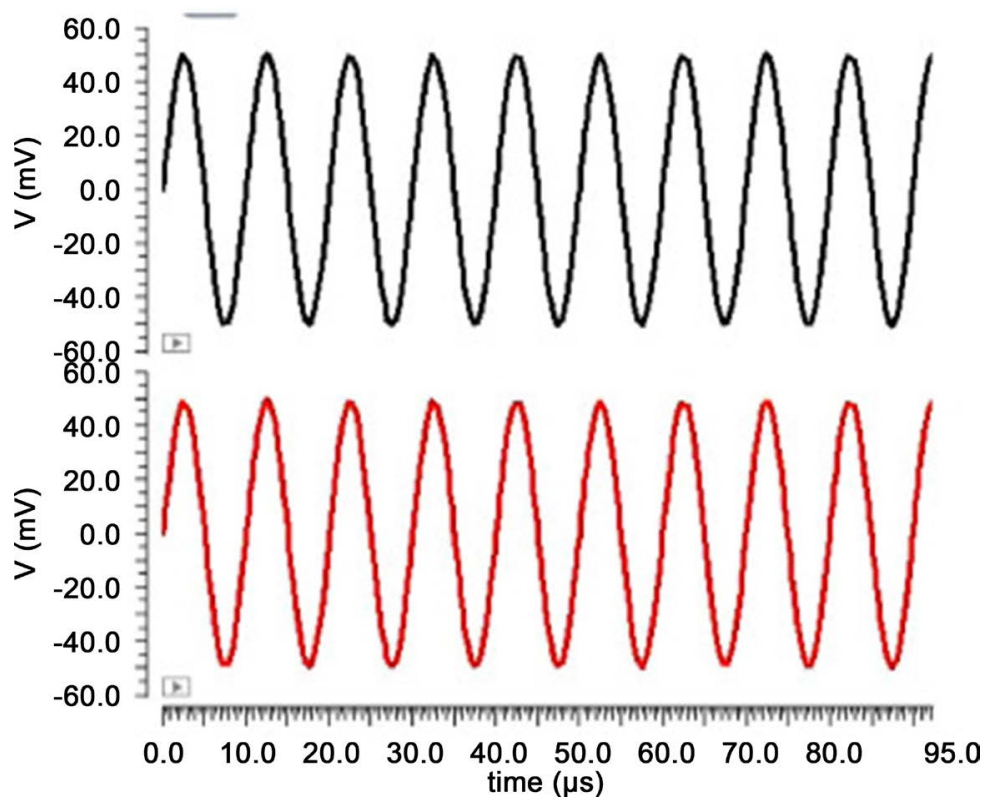

Figure 8. Transient response of the input and output for proposed VDVTA and OTA based all pass filter. 
Table 2. Comparison of the proposed All Pass filter Configuration With various All Pass filter configuration.

\begin{tabular}{cccccc}
\hline Ref No & $\begin{array}{c}\text { No of Active } \\
\text { Components }\end{array}$ & $\begin{array}{c}\text { No Passive Components } \\
\text { floating or Grounded: } \\
\text { R - C }\end{array}$ & $\begin{array}{c}\text { Grounded } \\
\text { Capacitor }\end{array}$ & $\begin{array}{c}\text { Electronic } \\
\text { tunability }\end{array}$ & $\begin{array}{c}\text { Component } \\
\text { Matching } \\
\text { Condition }\end{array}$ \\
\hline 1 & CFTA & 1 Resistor, 1 Capacitor & Yes & Yes & No \\
2 & VDTA & 1 Capacitor & No & Yes & No \\
8 & DDCC & 3 Resistor, 1 Capacitor & Yes & No & No \\
9 & OTA & 1 Capacitor & Yes & Yes & No \\
10 & CDTA & 1 Capacitor & No & Yes & No \\
11 & VDIBA & 1 Capacitor & No & Yes & No \\
24 & FDCCII & 2 Resistor, 1 Capacitor & Yes & No & No \\
25 & CDBA & 3 Resistor, 1 Capacitor & No & No & Yes \\
Proposed Work & VDVTA, OTA & 1 Capacitor & Yes & Yes & Yes \\
\hline
\end{tabular}

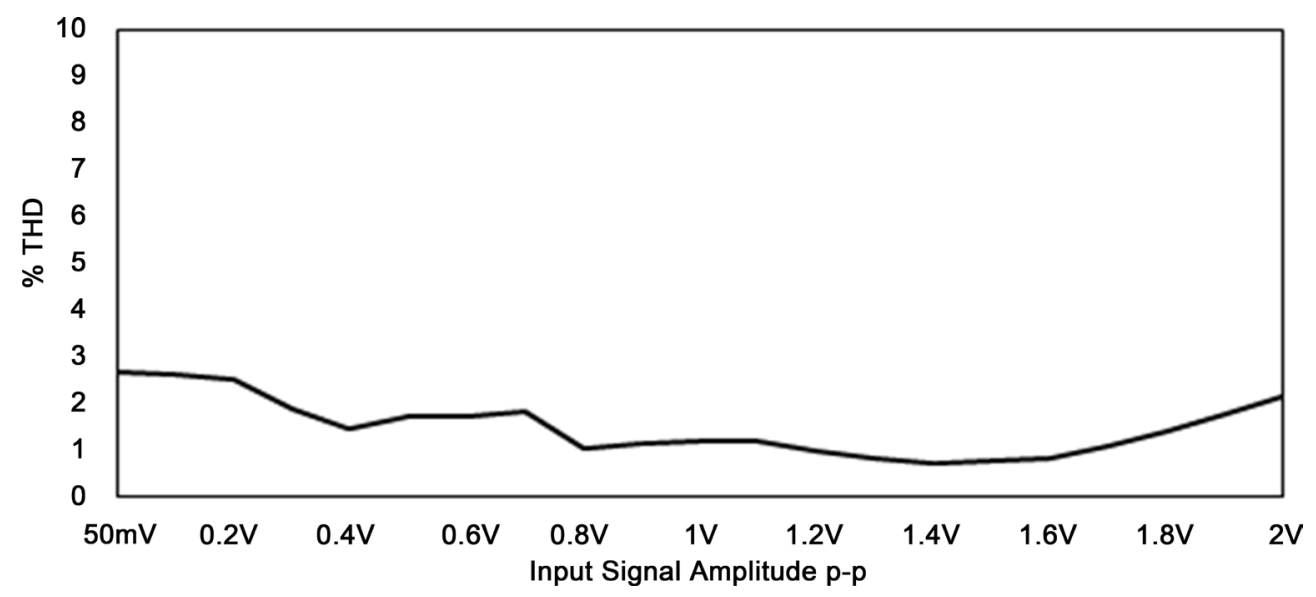

Figure 9. \% THD at the input signal of all pass filter.

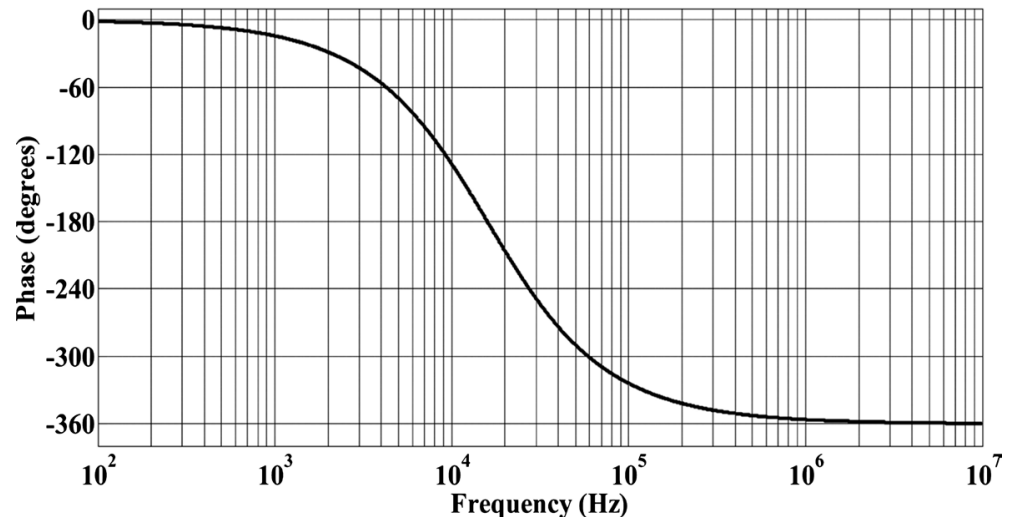

Figure 10. Simulated phase margin of proposed all pass filter configurations.

frequency $1.53 \mathrm{KHz}-10.498 \mathrm{MHz}$ and Theoretical $\left(F_{\text {in }}\right)$ approximately 1.499 $\mathrm{KHz}$ with power supply $\pm 0.85 \mathrm{~V}$ and Bias voltage $\pm 0.5 \mathrm{~V}$.

The device model parameters are taken from TSMC $0.18 \mu \mathrm{m}$ have been simu- 
lated in PSPICE with high linearity at $\pm 0.5 \mathrm{~V}$ Supply Voltage at different bias current. The simulated parameters of the proposed VDVTA and OTAs based first order all pass filters are reported in Table 3. are taken from TMSC $0.18 \mu \mathrm{m}$ CMOS technology parameters at $\pm 0.5 \mathrm{~V}$ supply voltages all gm equal to 639.7 $\mu \mathrm{A} / \mathrm{V}$ or $734 \mu \mathrm{A} / \mathrm{V}$ are used for the proposed VDVTA and OTAs based first order all pass filters yield high linearity.

\section{Performance Evaluation}

The performance of the proposed VDVTA and OTAs based first order all pass

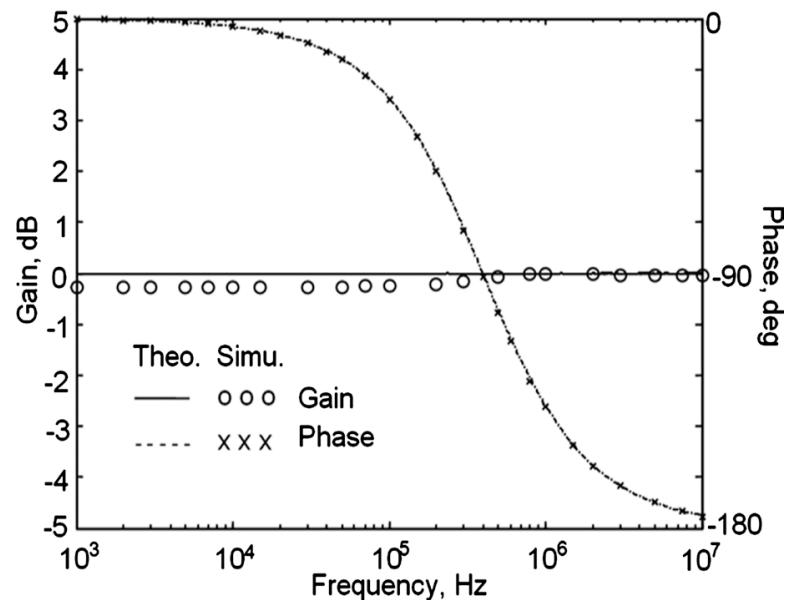

Figure 11. Simulated frequency response with phase of proposed all pass filter.

Table 3. Simulated Parameters of Proposed VDVTA and OTA based All Pass Filter at Different Bias Currents: $I_{\text {Bias }}=10 \mu \mathrm{A}-300 \mu \mathrm{A}$.

\begin{tabular}{|c|c|c|}
\hline S. No & Specifications & Simulated \\
\hline 1 & CMOS Technology & $0.18 \mu \mathrm{m}$ \\
\hline 2 & Transconductances $(\mu \mathrm{A} / \mathrm{V})$ & $68.16 \mu \mathrm{A} / \mathrm{V}-789 \mu \mathrm{A} / \mathrm{V}$ at $10 \mu \mathrm{A}-300 \mu \mathrm{A}$ \\
\hline 3 & Bias current $(\mu \mathrm{A})$ & $10 \mu \mathrm{A}-300 \mu \mathrm{A}$ \\
\hline 4 & $\%$ Total Harmonic Distortion & $1.21 \%-2.83 \%$ \\
\hline 5 & Power dissipation (mW) & $1.6 \mathrm{~mW}-4.76 \mathrm{~mW}$ \\
\hline 6 & Maximum Input noise (nV) & $33 \mathrm{nV}-42 \mathrm{nV}$ \\
\hline 7 & Maximum output noise $(\mathrm{nV})$ & $24 \mathrm{nV}$ \\
\hline 8 & Maximum Supply Voltage (V) & $\pm 0.85 \mathrm{~V}$ \\
\hline 9 & Bias Voltage $(\mathrm{V})$ & $\pm 0.50 \mathrm{~V}$ \\
\hline 10 & Phase Margin & $23-45$ \\
\hline 11 & Input output Voltage Swing $(\mathrm{mV})$ & $0-60 \mathrm{mV}$ \\
\hline 12 & Open loop Gain (dB) & $\begin{array}{c}5.045-6.020 \mathrm{~dB} \text { with typical values } 30 \mathrm{~dB}-71 \\
\mathrm{~dB}\end{array}$ \\
\hline 13 & Frequency $(\mathrm{KHz})$ & $1.53 \mathrm{KHz}$ and $10.498 \mathrm{MHz}$ \\
\hline 14 & Noise Spectral Density & $4.10 \mathrm{nV} / \sqrt{\mathrm{Hz}}$ at the input and $3.8 \mathrm{nV} / \sqrt{\mathrm{Hz}}$ \\
\hline
\end{tabular}


filters are taken from TMSC $0.18 \mu \mathrm{m}$ CMOS technology parameters. The both types of configurations yield low noise and high stability at the desired range of pole frequencies. Transconductance gain is directly proportional to the bias current. The simulated results of all pass filters by OTA observed agree with the simulated results of VDVTA based all pass filter.

\section{Conclusions}

The workability and functionality of the proposed OTAs and VDVTA based all pass filter are verified with CMOS simulation in the SPICE 0.18 um CMOS Technology. In an analog Signal Processing, first order all pass filter is widely used to shift the phase of input signal.

The reported OTAs and VDVTA based all pass filter yields some advantageous features:

1) Fully integrated with monolithic ICs.

2) Electronic tunability with different pole frequencies at different bias currents.

3) The proposed VDVTA based all pass filter configuration exhibits low input impedance and high output impedance.

4) The proposed VDVTA based all pass filter configuration exhibits good sensitivity performance.

5) The reported work represents wideband bulk-driven OTA with tunable transconductance was designed.

6) The natural frequency $\left(\omega_{0}\right)$ of the reported OTAs and VDVTA based all pass filter can be tuned with $g_{m 2}$ or $g m_{2}$ and with capacitor C2 at constant bandwidth.

7) Bandwidth can be controlled with the help of transconductance $\left(g_{m 1}\right)$ and quality factor $(\mathrm{Q})$ can be controlled independent of natural frequency $\left(\omega_{0}\right)$ with transconductance $\left(g_{m 1}\right)$.

8) For the first configuration using single VDVTA, we can change cut off frequency or pole frequency by changing $g_{m}$.

9) Whereas in second configuration OTAs based all pass filter, the cut off frequency or pole frequency can be changed by tuning $g_{m 1}$ or $g_{m 2}$.

10) The integration of proposed OTA and VDVTA based first order all pass filter is open area in future research using modern mixed analog signal processing based integrated circuits for achieving high linearity at low voltage.

\section{Conflicts of Interest}

The author declares no conflicts of interest regarding the publication of this paper.

\section{References}

[1] Iamarejin, A., Maneewan, S., Suwanjan, W.P. and Jaikla, W. (2013) Current-Mode Current Gain First-Order All Pass Filter Employing CFTAs. Przeglad Elektrotechniczny, 89, 187-190.

[2] Maneewan, S., Udorn, N., Dungmalai, D. and Silapanp, J.W. (2014) A Vol- 
tage-Mode First Order All Pass Filter Based on VDTA. Advance in Electrical and Electronic Engineering, 12, 40-46. https://doi.org/10.15598/aeee.v12i1.846

[3] Maheshwari, S. (2007) Voltage-Mode All-Pass Filters Including Minimum Component Count Circuits. Active and Passive Electronic Component, 2007, Article ID: 79159.

[4] Mohan, J., Maheshwari, S. and Chauhan, D.S. (2015) Voltage-Mode Cascadable All-Pass Section Using Single Active Element and Grounded Passive Component. Circuits and Systems, 1, 5-11. https://doi.org/10.4236/cs.2010.11002

[5] Singh, G., Prasad, D. and Bhaskar, D.R. (2015) Single VDVTA Based Voltage-Mode Biquad Filter. Circuit and System, 6, 55-59. https://doi.org/10.4236/cs.2015.63006

[6] Singh, S.V., Maheshwari, S. and Chauhan, D.S. (2011) Single MO-CCCCTA-Based Electronically Tunable Current/Trans-Impedance-Mode Biquad Universal Filter. Circuit and System, 2, 1-6. https://doi.org/10.4236/cs.2011.21001

[7] Maheshwari, S., Singh, S.V. and Chauhan, D.S. (2011) Electronically Tunable Low Voltage Mixed-Mode Universal Biquad Filter. IET Circuits, Devices and Systems, 5, 149-158. https://doi.org/10.1049/iet-cds.2010.0061

[8] Kumngern, K. and Torteanchai, U. (2011) Current-Tunable Current-Mode All-Pass Section Using DDCC. International Conference on Electronic Devices, Systems, and Applications, Kuala Lumpur, 25-27 April 2011, 217-220. https://doi.org/10.1109/ICEDSA.2011.5959038

[9] Tsukutani, T., Tsukutani, H., Sumi, Y. and Yabuki, N. (2010) Electronically Tunable First-Order All Pass Section Using OTAs. Computer Applications and Industrial Electronics (ICCAIE 2010), Kuala Lumpur, 5-7 December 2010, 548-511. https://doi.org/10.1109/ICCAIE.2010.5735141

[10] Tangsrirat, W., Tanjaroen, W. and Pukkalanum, T. (2009) Current-Mode Multi Phase Sinusoidal Oscillator Using CDTA-Based All Pass Sections. International Journal of Electronics and Communications, 63, 616-622. https://doi.org/10.1016/j.aeue.2008.05.001

[11] Herencsar, N., Minaei, S., Koton, J., Yuce, E. and Vrba, K. (2012) New Resistorless and Electronically Tunable Realization of Dual-Output VM All-Pass Filter Using VDIBA. Analog Integrated Circuits and Signal Processing, 74, 141-154. https://doi.org/10.1007/s10470-012-9936-2

[12] Mohan, J. and Maheshwari, S. (2013) Cascadable Current-Mode First Order All-Pass Filter Based on Minimal Components. The Scientific Word Journal, 2013, Article ID: 859784. https://doi.org/10.1155/2013/859784

[13] Herencsar, N., Koton, J., Jerabek, J., Vrba, K. and Cicekoglu, O. (2011) Voltage-Mode All-Pass Filters Using Universal Voltage Conveyor and MOSFET-Based Electronic Resistors. Radioengineering, 20, 10-18.

[14] Mohan, J., Maheshwari, S. and Chauhan, D.S. (2010) Voltage Mode Cascadable All-Pass Sections Using Single Active Element and Grounded Passive Components. Circuits and Systems, 1, 5-11. https://doi.org/10.4236/cs.2010.11002

[15] Tsukutani, T., Tsunetsugu, H., Sumi, Y. and Yabuki, N. (2010) Electronically Tunable First-Order All-Pass Circuit Employing DVCC and OTA. International Journal of Electronics, 97, 285-293. https://doi.org/10.1080/00207210903289409

[16] Minaei, S. and Yuce, E. (2010) Novel Voltage-Mode All-Pass Filter Based on Using DVCCs. Circuits, Systems, and Signal Processing, 29, 391-402. https://doi.org/10.1007/s00034-010-9150-3

[17] Minaei, S. and Cicekoglu, O. (2006) A Resistorless Realization of the First-Order 
All-Pass Filter. International Journal of Electronics, 93, 177-183. https://doi.org/10.1080/00207210600562173

[18] Maheshwari, S. (2008) High Input Impedance Voltage-Mode First-Order All-Pass Sections. International Journal of Circuit Theory and Applications, 36, 511-522. https://doi.org/10.1002/cta.452

[19] Minaei, S. and Yuce, E. (2010) Unity/Variable-Gain Voltage-Mode/Current-Mode First-Order All-Pass Filters Using Single Dual-X Second-Generation Current Conveyor. IETE Journal of Research, 56, 305-312. https://doi.org/10.1080/03772063.2010.10876319

[20] Biolek, D. and Biolkova, V. (2010) First-Order Voltage-Mode All-Pass Filter Employing One Active Element and One Grounded Capacitor. Analog Integrated Circuits and Signal Processing, 65, 123-129. https://doi.org/10.1007/s10470-009-9435-2

[21] Metin, B. and Cicekoglu, O. (2009) Component Reduced All-Pass Filter with a Grounded Capacitor and High-Impedance Input. International Journal of Electronics, 96, 445-455. https://doi.org/10.1080/00207210802640595

[22] Singh, G. (2018) Realization of Grounded Inductor Based Band Pass Filter Design to Achieve Optimum Linearity with Bandwidth Using Single VDVTA. International Journal of Science, Technology and Management, 7, 37-43.

[23] Beg, P., Siddiqi, M.A. and Ansari, M.S. (2011) Multi Output Filter and Four Phase Sinusoidal Oscillator Using CMOS DX-MOCCII. International Journal of Electronics, 98, 1185-1198. https://doi.org/10.1080/00207217.2011.582451

[24] Kacar, F. and Yesil, A. (2012) FDCCII Based Electronically Tunable Voltage Mode Biquad Filter. International Journal of Circuit Theory and Application, 40, 377-383.

[25] Pandey, R., Pandey, N., Negi, T. and Garg, V. (2013) CDBA Based Universal Inverse Filter. ISRN Electronics, 2013, Article ID: 181869.

https://doi.org/10.1155/2013/181869 